\title{
Human Vascular Endothelial Growth Factor Protects Axotomized Retinal Ganglion Cells In Vivo by Activating ERK-1/2 and Akt Pathways
}

\author{
Ülkan Kilic, ${ }^{1}$ Ertugrul Kilic, ${ }^{1}$ Anne Järve, ${ }^{2}$ Zeyun Guo, ${ }^{1}$ Annett Spudich, ${ }^{1}$ Katja Bieber, ${ }^{2}$ Uxue Barzena, ${ }^{2}$ \\ Claudio L. Bassetti, ${ }^{1}$ Hugo H. Marti, ${ }^{2}$ and Dirk M. Hermann ${ }^{1}$ \\ ${ }^{1}$ Department of Neurology, University Hospital Zurich, CH-8091 Zurich, Switzerland, and 2 Institute of Physiology and Pathophysiology, University of \\ Heidelberg, D-69120 Heidelberg, Germany
}

\begin{abstract}
Based on its trophic effects on neurons and vascular cells, vascular endothelial growth factor (VEGF) is a promising candidate for the treatment of neurodegenerative diseases. To evaluate the therapeutic potential of VEGF, we here examined effects of this growth factor on the degeneration of axotomized retinal ganglion cells (RGCs), which, as CNS-derived neurons, offer themselves in an excellent way to study neuroprotection in vivo. Making use of a transgenic mouse line that constitutively expresses human VEGF under a neuron-specific enolase promoter, we show that (1) the VEGF-transgenic retina overexpresses human VEGF, (2) RGCs carry the VEGF receptor-2, and (3) vascular networks in normal and axotomized VEGF-transgenic $(\mathrm{tg})$ retinas do not differ from control animals. After axotomy, RGCs of VEGF-tg mice were protected against delayed degeneration, as compared with wild-type littermates. Western blots revealed increased phosphorylated ERK-1/2 and Akt and reduced phosphorylated p38 and activated caspase-3 levels in axotomized VEGF-transgenic retinas. Intravitreous injections of pharmacological ERK-1/2 (PD98059) or Akt (LY294002) inhibitors showed that VEGF exerts neuroprotection by dual activation of ERK-1/2 and Akt pathways. In view that axotomy-induced RGC death occurs slowly and considering that RGCs are CNS-derived neurons, we predict the clinical implementation of VEGF in neurodegenerative diseases of both brain and retina.
\end{abstract}

Key words: neurodegeneration; neuroprotection; neurotrophic; VEGF; signal transduction; mitogen activated protein kinase; phosphatidylinositol-3 kinase

\section{Introduction}

In view of its trophic influence on neurons and vascular cells, vascular endothelial growth factor (VEGF) has previously attracted strong interest in brain diseases (Sun et al., 2003; Storkebaum and Carmeliet, 2004; Wang et al., 2005). VEGF is constitutively expressed in the brain and upregulated during hypoxia as part of an endogenous adaptive response (Marti and Risau, 1998; Cramer and Chopp, 2000). VEGF exhibits neuroprotective activity in vitro (Jin et al., 2000; Matsuzaki et al., 2001; Wick et al., 2002) and protects degenerating motoneurons in rodent models of amyotrophic lateral sclerosis (ALS), the SOD $1{ }^{\mathrm{G} 93 \mathrm{~A}}$ mouse (Azzouz et al., 2004) and rat (Storkebaum et al., 2005). Based on these findings, VEGF is now considered as therapeutic against ALS, raising hopes that this severely devastating disease may someday be cured.

\footnotetext{
Received Jan. 31, 2006; revised 0ct. 8, 2006; accepted 0ct. 11, 2006.

This work was supported by the Swiss National Center of Competence in Research "Neural plasticity and repair" (3200B0-112056), the Center of Integrative Human Physiology Zurich, the Hartmann-Müller-Stiftung (all to D.M.H.), and by a grant from the Ministry of Science, Research and the Arts of Baden-Württemberg (23-7532.2220-12/1; to H.H.M.). We thank A. Fendel and B. Saam for technical assistance and G. Froelich for artwork. We have no conflict of interest.

Correspondence should be addressed to Dr. Dirk M. Hermann, Department of Neurology, University Hospital Zurich, Frauenklinikstrasse 26, CH-8091 Zurich, Switzerland. E-mail: dirk.hermann@usz.ch.

DOI:10.1523/JNEUROSCI.0434-06.2006

Copyright $\odot 2006$ Society for Neuroscience $\quad 0270-6474 / 06 / 2612439-08 \$ 15.00 / 0$
}

In the pathogenesis of ALS, VEGF deficiency may play a causative role. As such, low VEGF levels are capable of inducing an ALS-like state in gene-targeted mice in which the hypoxiaresponsible element is deleted from the VEGF promoter (Oosthuyse et al., 2001), and may also confer an elevated risk for developing ALS in humans (Lambrechts et al., 2003). Despite their only mildly reduced VEGF levels under physiological conditions, chronically decreased blood flow levels were noted in the spinal cords of VEGF deficient mice (Oosthuyse et al., 2001) and motor cortex of ALS patients (Waldemar et al., 1992; Kobari et al., 1996), which were suggested to be causatively involved in the process of motoneuron injury.

Are the neuroprotective properties of VEGF in vivo linked to its ability to promote vascular remodeling in hemodynamically compromised tissue, or does VEGF also confer protection when blood supply is intact? To elucidate this question, we here examined effects of transgenic VEGF in a model of retinal ganglion cell (RGC) axotomy induced by optic nerve (ON) transection. ON transection is a highly reproducible model of subacute neuronal degeneration (Garcia-Valenzuela et al., 1994; Isenmann et al., 1997; Ü. Kilic et al., 2005). Ontogenetically, RGCs are CNSderived neurons that, because of their accessibility outside the cranial cavity, offer themselves in an excellent way to study mechanisms of neuronal injury and neuroprotection in vivo. After axotomy close to the eye, RGCs exhibit a stereotypic pattern of 
gene responses resulting in apoptotic death of almost $80 \%$ of ganglion cells within 2 weeks after trauma. There is no collateral damage in this model, because the $\mathrm{ON}$ is cut at distance to the degenerating RGCs.

We studied a mouse line constitutively expressing human VEGF $_{165}$ under the control of a neuron-specific enolase (NSE) promoter [transgenic V1 (V1tg) mouse] (Vogel et al., 2004). This mouse expresses elevated levels of human VEGF in the brain and, as we now show, retina. We first analyzed vascular networks in the normal and axotomized V1tg retina. We then examined the expression and/or activation of VEGF receptor-2 (VEGFR-2), of the signal factors extracellular-regulated kinase (ERK)-1/2, Akt and p38, and of caspase-3 (E. Kilic et al., 2005). Finally, we modulated the activity of two of these factors, ERK-1/2 and Akt, by delivering pharmacological inhibitors into the animals' vitreous space, studying the role of ERK-1/2 and phosphatidylinositol-3 kinase (PI3K)/Akt pathways in the neuroprotection of VEGF.

\section{Materials and Methods}

Animals. Animal experiments were performed according to National Institutes of Health guidelines for the care and use of laboratory animals with government approval (Cantonal Veterinary Office, ZH102/2003). NSE-VEGF V1tg mice, which were produced on a C57BL/6 background (Vogel et al., 2004; Wang et al., 2005), were used. Nontransgenic (ntg) wild-type littermates of V1tg mice served as controls. For all experiments, male mice aged 12-16 weeks were used.

In situ hybridization histochemistry of VEGF $m R N A$. ntg and V1tg animals were deeply anesthetized with chloral hydrate and killed $(n=3$ animals per mouse line). Both eyes were removed, fresh-frozen, and cut on a cryostat into $10 \mu \mathrm{m}$ sections. On these sections, VEGF mRNA was detected by in situ hybridization using $\left[{ }^{35} \mathrm{~S}\right]$-UTP-labeled RNA probes recognizing both human and mouse VEGF mRNA, as described previously (Marti and Risau, 1998).

ELISA of human VEGF protein. From additional eyes of ntg and V1tg mice ( $n=6$ animals per mouse line), protein lysates were obtained. In the supernatants, human VEGF was quantified using a commercially available immunoassay kit specific for human VEGF (Quantikine; R \& D Systems, Minneapolis, MN) (Marti et al., 2000).

Immunocytochemistry for VEGFR-2. Fresh-frozen ntg and V1tg retinas ( $n=6 /$ mouse line) were cut on a cryostat into $18 \mu \mathrm{m}$ sections. After fixation in acetone and blocking in 0.1 м PBS containing 0.3\% Triton-X100/10\% normal goat serum, sections were labeled overnight at $4^{\circ} \mathrm{C}$ with monoclonal rat anti-mouse VEGFR-2 (Flk-1) antibody (Marti et al., 2000), diluted 1:100, that was detected with a cyanine 3-labeled secondary antibody. Sections were counterstained with 4',6-diamidino-2-phenylindole (DAPI) and coverslipped. Sections were evaluated by counting the number of VEGFR-2(+) RGCs in sectors of the retina of $200 \mu \mathrm{m}$ length.

Retrograde labeling of RGCs. ntg and V1tg mice were anesthetized with $1 \%$ halothane $\left(30 \% \mathrm{O}_{2}\right.$, remainder $\left.\mathrm{N}_{2} \mathrm{O}\right)$. After placing the animals in a stereotactic frame, a bur hole was drilled into the pericranium overlying the superior colliculi $(0.7 \mathrm{~mm}$ lateral to sagittal suture, $3 \mathrm{~mm}$ posterior to bregma). For retrograde labeling of RGCs, a Hamilton syringe was inserted $2.0 \mathrm{~mm}$ beneath the brain surface, and $0.7 \mu \mathrm{l}$ of fluorogold (Fluorochrome, Denver, CO) was injected stereotactically into both superior colliculi (infusion rate, $0.7 \mu \mathrm{l} / \mathrm{min}$ ) (Ü. Kilic et al., 2005). After infusion, the injection needle remained inside the brain for $2 \mathrm{~min}$ to prevent fluorogold diffusion along the needle track. The syringe was then withdrawn and wounds were carefully sutured.

ON transection. Three days after RGC labeling, ntg and V1tg mice were re-anesthetized with $1 \%$ halothane. After skin incision close to the superior orbital rim, the right orbita was opened, leaving the supraorbital vein intact, and the lacrimal gland was resected subtotally. After spreading the superior extraocular muscles, the right $\mathrm{ON}$ was transected under microscopical control $\sim 0.5 \mathrm{~mm}$ distant to the posterior pole of the eye, taking care not to damage retinal blood vessels (Ü. Kilic et al., 2005). The wounds were sutured, and retinal blood supply was verified by fundoscopy, which was performed microscopically while flattening the cornea with a glass slide. Fundoscopies revealed intact filling of blood vessels around the optic disc. In three animals that were not used for additional studies, laser Doppler flow (LDF) during axotomy was monitored with a flexible fiberoptic probe (Perimed, Stockholm, Sweden) that was inserted into the eye through a small incision close to the cornea-sclera junction. LDF did not show any major changes during axotomy (LDF 2 min after ON transection, $96 \pm 24 \%$ of preaxotomy levels).

Tissue processing. Fourteen days after axotomy, mice were killed by an overdose of chloral hydrate and both eyes were removed. Retinas were dissected, flat-mounted on glass slides, and fixed in $4 \%$ paraformaldehyde/0.1 M PBS for $30 \mathrm{~min}(n=6$ animals per mouse line for evaluation of RGC survival). Retinal flat-mounts were evaluated by one of the investigators blinded for the experimental conditions (Ü.K.) by fluorescence microscopy. RGC densities were determined by counting tracerlabeled RGCs in 12 distinct areas of $62,500 \mu \mathrm{m}^{2}$ each (three areas per retinal quadrant at $1 / 6,3 / 6$, and $5 / 6$ of the retinal radius, respectively) both on the axotomized and contralateral nonaxotomized side, subsequently calculating mean values for all three eccentricities as well as over the whole retina ( $\ddot{\mathrm{U}}$. Kilic et al., 2005).

In vivo angiography with FITC-labeled dextran. Additional ntg and V1tg mice were axotomized ( $n=5$ animals each). Fourteen days later, animals were deeply anesthetized with $3 \%$ halothane. The left heart ventricle was cannulated, and animals were transcardially perfused with 10 $\mathrm{ml}$ of $0.1 \mathrm{M}$ PBS, followed by $1 \mathrm{ml}$ of fluorescein isothiocyanate (FITC)dextran $\left(10 \mathrm{mg} / \mathrm{ml}\right.$, molecular weight $2 \times 10^{6}$; Sigma, Deisenhofen, Germany), dissolved in 0.1 м PBS. Both eyes were then removed. Retinas were dissected, flat-mounted, and fixed with $4 \%$ paraformaldehyde. Retinal flat mounts were evaluated by one investigator blinded for the experimental conditions (Z.G.) by fluorescence microscopy. The diameter of four main retinal arterioles was determined at various retinal eccentricities (at $1 / 6,3 / 6$, and $5 / 6$ of the retinal radius) both in the axotomized and nonaxotomized eye (the four largest branches of the central artery were analyzed in all flat mounts). In addition, the density of retinal capillaries was evaluated at the same three eccentricities by counting the number of vessels crossing a straight $250 \mu \mathrm{m}$ line. For all measurements taken, mean values were calculated for all three eccentricities. This procedure allowed us to obtain detailed information on the retinal vascular network both surrounding and at distance to the posterior eye pole.

Western blots. Additional ntg and V1tg animals were deeply anesthetized $14 \mathrm{~d}$ after ON transection and killed ( $n=5-6$ each). Eyes were removed and retinas dissected. Protein lysates were obtained from the axotomized and nonaxotomized retinas. Lysates were pooled, resolved by SDS-PAGE, and transferred onto polyvinylidene fluoride membranes. Membranes were dried, incubated in blocking solution, and immersed with rabbit anti-total (equally detecting both the unphosphorylated and phosphorylated forms) ERK-1/2 (9102; Cell Signaling, Allschwil, Switzerland), mouse anti-phospho-ERK-1/2 (M8159; Sigma), rabbit anti-total Akt (9272; Cell Signaling), rabbit anti-phospho-Akt (9271; Cell Signaling), rabbit anti-total p38 (9212; Cell Signaling), rabbit anti-phospho-p38 (9211; Cell Signaling), and rabbit anti-activated caspase-3 (CM-1; BD Biosciences, Basel, Switzerland) antibodies, each diluted 1:500 (E. Kilic et al., 2005). Membranes were rinsed, incubated in secondary antibodies, and exposed. Protein loading was controlled using a mouse anti- $\beta$-actin antibody (A5316; Sigma). Blots were performed three times to confirm data reproducibility. Protein levels were analyzed densitometrically, corrected with values determined on $\beta$-actin blots, and expressed as relative values compared with ntg mice.

Inhibition of ERK-1/2 and PI3K/Akt pathways. In additional fluorogold-prelabeled V1tg animals subjected to ON transection, $0.5 \mu \mathrm{l}$ of either (1) 100\% dimethylsulfoxide (DMSO; $n=6$ animals), (2) the mitogen-activated protein (MAP) kinase/ERK kinase-1 inhibitor PD98059 (50 mM, dissolved in 100\% DMSO; New England Biolabs, Schwalbach, Germany; $n=3$ ), or (3) the PI3K/Akt inhibitor LY294002 ( $100 \mathrm{~mm}$, dissolved in $100 \%$ DMSO; Sigma; $n=6$ ), was carefully injected into the vitreous space by means of a glass microelectrode (tip diameter, $50 \mu \mathrm{m}$ ), puncturing the eye at the cornea-sclera junction. The injections were done on days $0,4,7$, and 10 after axotomy. This strategy has been used previously by others (Klöcker et al., 2000) and us (Ü. Kilic et al., 2005) without complications to characterize the role of the ERK-1/2 and 


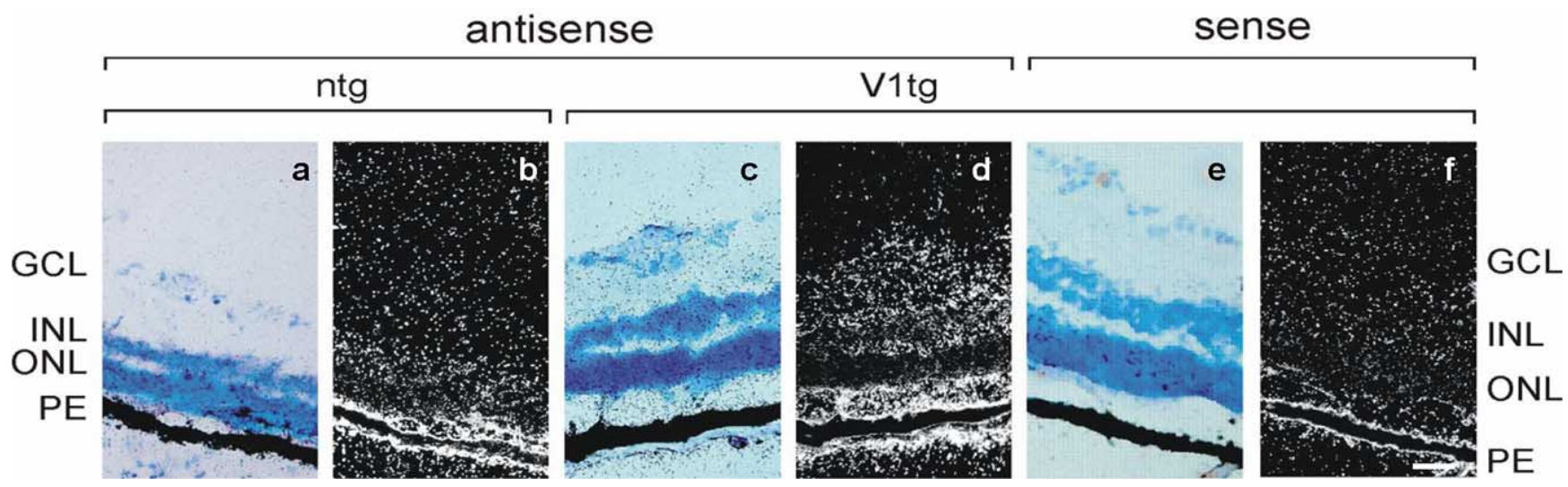

Figure 1. Increased VEGF mRNA levels in the retina of V1tg mice. $\boldsymbol{a}-\boldsymbol{f}$, Retinal expression was studied by in situ hybridization analysis in ntg littermates $(\boldsymbol{a}, \boldsymbol{b})$ and V1tg mice $(\boldsymbol{c}-\boldsymbol{f})$ using a ${ }^{35}$ S-labeled riboprobe recognizing both mouse and human VEGF mRNA. Anatomical $(\boldsymbol{a}, \boldsymbol{c}, \boldsymbol{e})$ and dark-field $(\boldsymbol{b}, \boldsymbol{d}, \boldsymbol{f})$ images labeled with antisense $(\boldsymbol{a}-\boldsymbol{d})$ and sense $(\boldsymbol{e}, \boldsymbol{f})$ probes are shown. Specific hybridization signals are present in the ONL, the INL, and GCL. Note the stronger expression of VEGF mRNA in the GCL in V1tg $(\boldsymbol{c}, \boldsymbol{d})$ as compared with ntg $(\boldsymbol{a}, \boldsymbol{b})$ mice. No specific signal is detectable with the VEGF mRNA sense probe $(\boldsymbol{e}, \boldsymbol{f})$. PE, pigment epithelium. Scale bar, $50 \mu \mathrm{m}$.

PI3K/Akt pathways in RGC survival. Animals were killed $14 \mathrm{~d}$ after axotomy, retinas removed, flat-mounted, and evaluated microscopically, as described above. In control experiments, $0.5 \mu \mathrm{l}$ DMSO, DMSO/PD98059 (50 mM), or $\mathrm{DMSO} / \mathrm{LY} 294002(100 \mathrm{mM})$ were intravitreously injected in nonaxotomized mice on days $0,4,7$, and 10 that were killed on day $14(n=3$ animals per group). Retinas were removed, flat-mounted, and evaluated under the fluorescence microscope, as above. In nonaxotomized ntg animals, DMSO, DMSO/PD98059, and DMSO/LY294002 delivery did not influence RGC survival (DMSO, $4823 \pm 398$ cells/mm ${ }^{2}$; DMSO/PD98059, $4908 \pm 457 /$ $\mathrm{mm}^{2}$; DMSO/LY294002, $4727 \pm 240 / \mathrm{mm}^{2}$ ).

To characterize the effects of ERK-1/2 and Akt inhibitors on VEGF mRNA expression as well as on ERK-1/2 and Akt phosphorylation, nonaxotomized V1tg eyes of additional animals were injected intravitreously with $0.5 \mu \mathrm{lDMSO}, \mathrm{DMSO} / \mathrm{PD} 98059$ (50 mM), or DMSO/LY294002 (100 mM) on days $0,4,7$, and 10 (VEGF mRNA, $n=2$ animals per group; ERK-1/2, Akt, $n=3$ per group). Animals were killed at $6 \mathrm{~h}$ (VEGF mRNA) or $1 \mathrm{~h}$ (ERK-1/2, Akt) after the last injection. Retinas were cut on a cryostat and processed by in situ hybridization histochemistry (VEGF mRNA) or homogenized and processed for Western blots (ERK-1/2, Akt).

Statistics. For statistical analysis, a standard software package (SPSS for Windows 12.0.1) was used. Differences between groups were compared by using one-way ANOVA, followed by least significant differences (LSD) tests (comparisons between at least three groups: analysis of RGC survival, vascular anatomy, Western blots) or two-tailed $t$ tests (comparisons between two groups: analysis of VEGFR-2 expression, Western blots in nonaxotomized mice, in which PD98059 and LY294002 were tested). Values are given as means $\pm \mathrm{SD}$. Values of $p<0.05$ were considered significant.

\section{Results}

Human VEGF is expressed in the V1tg mouse retina

To define as whether our V1tg mouse retina expresses human VEGF, we combined in situ hybridization techniques with ELISA. In situ hybridization exhibited weak VEGF mRNA signals in the retinal outer (ONL) and inner (INL) nuclear layers as well as very weak signals in the RGC layer (GCL) of ntg mice (Fig. 1). Compared with ntg animals, expression of VEGF mRNA was clearly increased in V1tg mice, particularly in the RGC layer (Fig. 1). In control experiments using a VEGF sense probe, in situ hybridization signals were absent in RGCs (Fig. 1). Quantitative analysis of the VEGF protein in whole eye extracts by ELISA showed that human VEGF was present in V1tg animals $(1.09 \pm 2.07 \mathrm{ng} / \mathrm{g}$ protein), but not detectable in ntg mice.

VEGFR-2 (Flk-1) is expressed on RGCs of ntg and V1tg mice To elucidate whether VEGFR-2, which has been suggested to mediate the neuroprotective function of VEGF in vitro (Jin et al.,
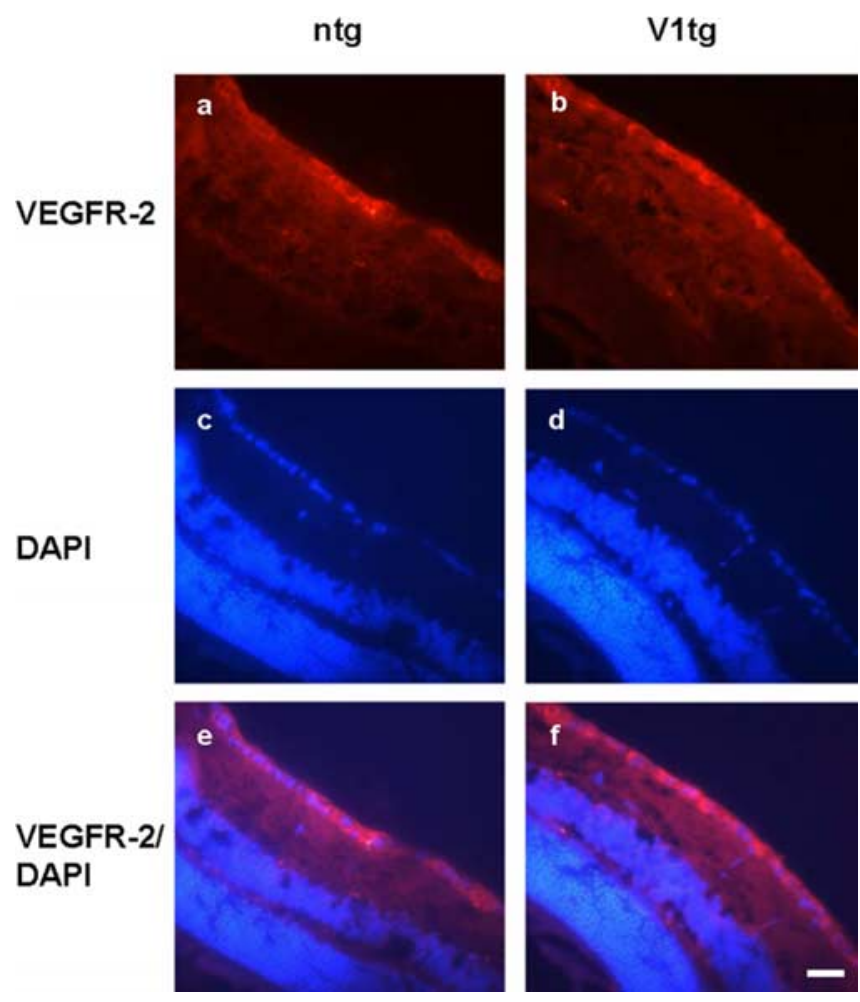

Figure 2. Mouse RGCS express the VEGFR-2. $\boldsymbol{a}-\boldsymbol{f}$, Immunohistochemistries revealing VEGFR-2 in the retina of ntg $(\boldsymbol{a}, \boldsymbol{c}, \boldsymbol{e})$ and $\operatorname{V1tg}(\boldsymbol{b}, \boldsymbol{d}, \boldsymbol{f})$ mice, counterstained with DAPI. Note that VEGFR-2 is expressed to a similar extent on RGCs of both ntg and V1tg mice. Scale bar, $40 \mu \mathrm{m}$.

2000), is expressed on RGCs in vivo, we prepared immunocytochemical stainings of mouse retinas. These stainings reproducibly revealed VEGFR-2 expression on RGCs (Fig. 2). The density of VEGFR-2 + RGCs did not differ between ntg and V1tg mice $(19.0 \pm 2.2$ vs $18.8 \pm 1.7$ cells $/ 250 \mu \mathrm{m}$ sector $)$.

\section{Vascular networks in V1tg mice do not exhibit any} structural abnormalities

In view of the known angiogenic effects of VEGF, we characterized the vasculature of ntg and V1tg retinas using angiographies with FITC-dextran, analyzing the size of the main retinal arterioles and capillary densities at various retinal eccentricities. In ntg mice, 


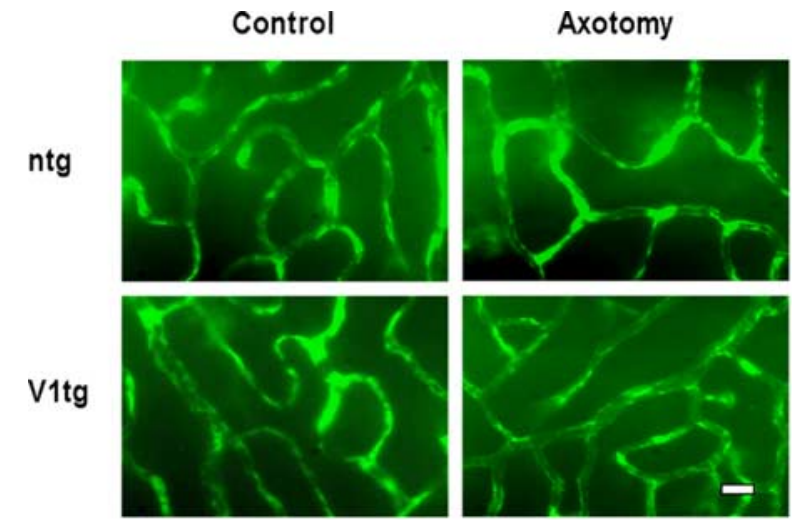

Diameter of main arterioles
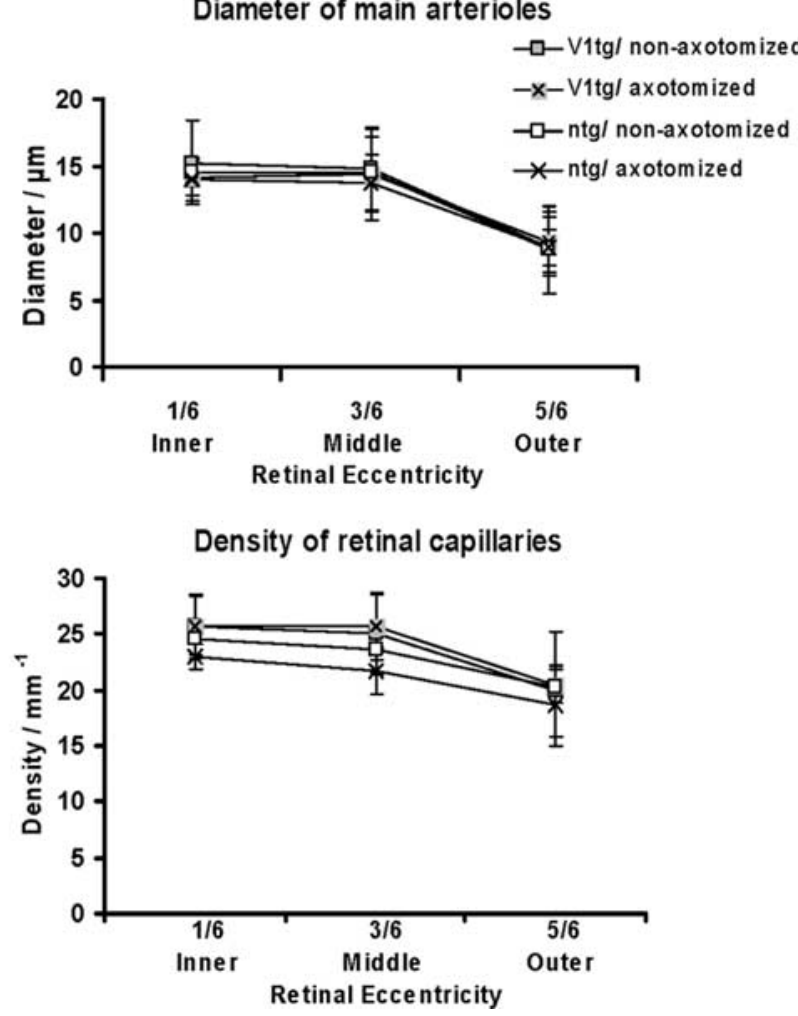

Figure 3. Vascular networks in the mouse retina are not influenced by $\mathrm{ON}$ transection and transgenic VEGF. Angiographies with FITC-dextran in ntg and V1tg mice of axotomized and nonaxotomized retinas $14 \mathrm{~d}$ after $0 \mathrm{~N}$ transection. Note the gradient of the diameter of the main arterioles and the capillary density, which continuously decreases from the posterior eye pole toward the eye periphery, in line with the fact that perfusion takes place through the central artery in direction of the outer eye segments. This gradient is maintained after $\mathrm{ON}$ transection and it is still present in response to VEGF, indicating the absence of major vascular abnormalities in the V1tg retina. Data are mean \pm SD values. No differences were detected between groups (one-way ANOVA). Scale bar, $30 \mu \mathrm{m}$.

the main arterioles of the retina revealed a gradient of their vessel diameter, which continuously decreased from the posterior eye pole toward the eye periphery (Fig. 3, center). This observation is in line with the fact that the retina is perfused through the central artery in direction of the outer eye segments. This pattern of vascularization was still present in axotomized animals and it was not influenced by human VEGF (Fig. 3, top, center).

Similar to the arteriole size, the density of capillaries was slightly higher close to the posterior eye pole than in the eye periphery in nonaxotomized ntg retinas (Fig. 3, bottom). The capillary density was not altered by $\mathrm{ON}$ transection and remained unchanged also in response to VEGF (Fig. 3, top, bottom). Our data indicate (1) the absence of major hemodynamic abnormalities in the axotomized mouse retina, which should have resulted in vascular remodeling, and (2) no evidence for vascular abnormalities in the V1tg retina, both in its physiological and axotomized states.

\section{Human VEGF promotes the survival of axotomized RGCs}

To find out whether VEGF protects axotomized RGCs from delayed degeneration, we evaluated the density of fluorogoldlabeled RGCs in mouse retinas by stereological analysis. Assessment of RGC densities in nonaxotomized eyes revealed no difference between $n t g$ and V1tg mice ( $5028 \pm 930$ vs $5089 \pm 378$ cells $/ \mathrm{mm}^{2}$; not significant). After axotomy, RGC density decreased to $26.8 \pm 9.2 \%$ of contralateral in ntg mice. VEGF significantly increased the percentage of surviving RGCs to $40.1 \pm$ $7.7 \%$ (Fig. 4 top, center) $(p<0.05)$. Neuroprotection was similarly seen in all retinal eccentricities (Fig. 4 , bottom), both close to the posterior pole of the eye and distant to it.

\section{VEGF stimulates ERK-1/2 and Akt and inhibits p38 and caspase-3 pathways}

To characterize signaling pathways underlying the neuroprotective function of VEGF, we prepared Western blots from tissue lysates obtained from axotomized and contralateral nonaxotomized retinas. In nonaxotomized retinas in V1tg mice, phosphorylated (but not total) ERK-1/2 and Akt levels were significantly higher than in ntg mice (Fig. 5). Phosphorylated p38, however, was lower in V1tg than ntg mice (Fig. 5). After axotomy, phosphorylated ERK-1/2 levels remained elevated in V1tg mice (Fig. 5). Phosphorylated Akt further increased above levels in nonaxotomized mice, whereas phosphorylated p 38 and activated caspase-3, which were both high in ntg mice, were attenuated by transgenic VEGF (Fig. 5).

\section{The ERK-1/2 and PI3K/Akt inhibitors PD98059 and} LY294002 reverse the neuroprotective function of VEGF To clarify whether the ERK-1/2 and PI3K/Akt pathways are involved in the survival-promoting activities of VEGF, we injected the solvent DMSO or DMSO containing the signal inhibitors PD98059 or LY294002 into the vitreous space of mice submitted to $\mathrm{ON}$ transection. Control experiments confirmed that PD98059 and LY294002 delivery inhibited ERK-1/2 and Akt phosphorylation (Fig. 6), without influencing VEGF mRNA expression (data not shown). Inhibition of either ERK-1/2 or PI3K/ Akt pathways completely abolished the neuroprotection of VEGF in axotomized V1tg animals, RGC survival rates being reversed to levels in ntg mice (Fig. 4). Our data confirmed that the neuroprotectivity of VEGF in vivo depends on the dual activation of ERK$1 / 2$ and Akt pathways.

\section{Discussion}

We demonstrate that human VEGF protects axotomized RGCs from delayed degeneration by activating ERK-1/2 and PI3K/Akt pathways. Our data were obtained using a transgenic mouse line that expresses human VEGF under an NSE promoter (Vogel et al., 2004), which we submitted to ON transection, a well defined in vivo model of CNS neuronal injury (Ü. Kilic et al., 2005). In previous studies, we showed that human VEGF is expressed in the brains of V1tg mice (Wang et al., 2005). We now expand our previous findings to the eye, providing evidence that the VEGF transgene is also present in RGCs of V1tg mice. As CNS-derived neurons, RGCs carry molecular biological printings of brain neu- 

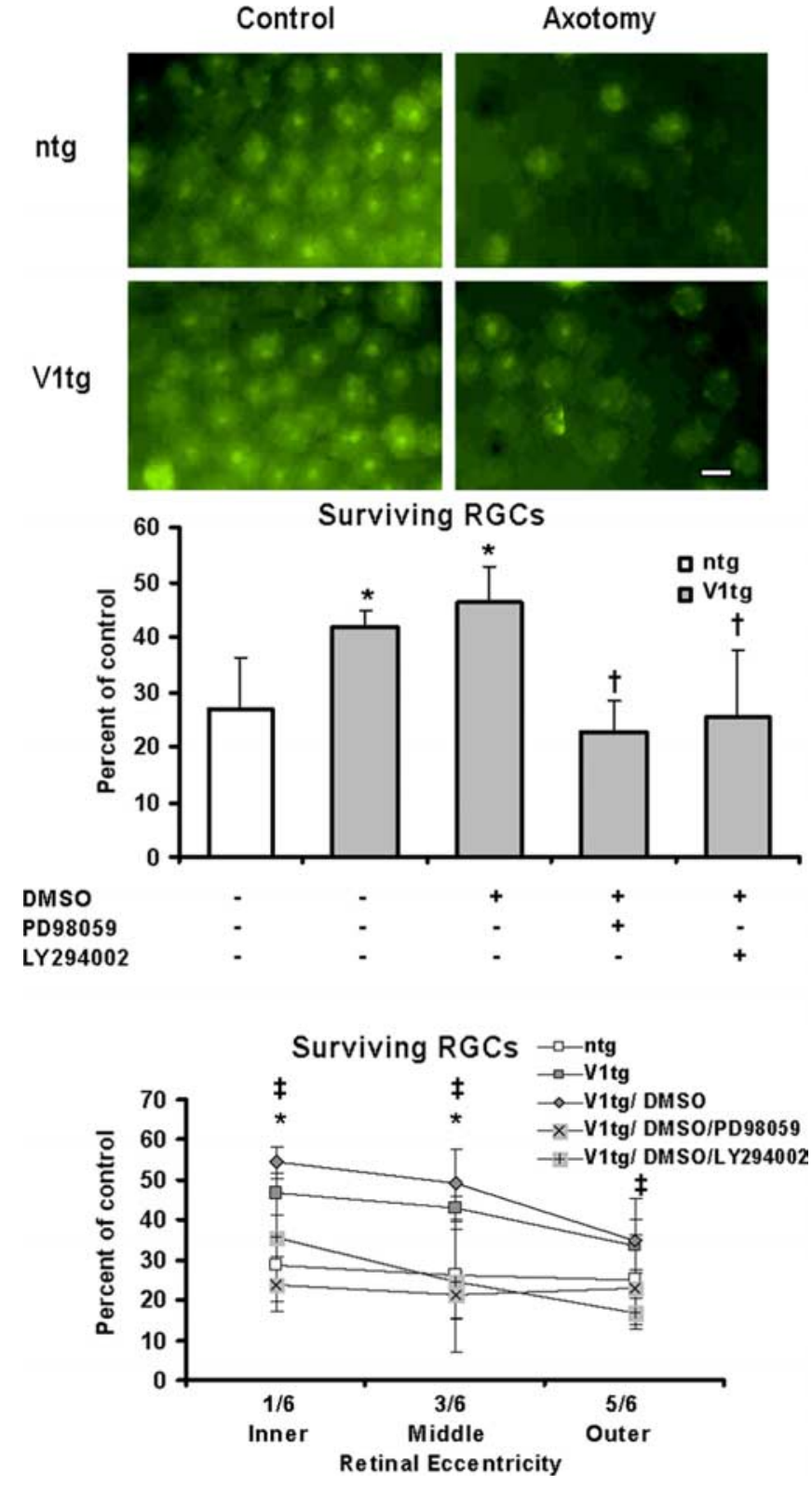

Figure 4. Human VEGF protects against the delayed degeneration of axotomized RGCS by activating ERK-1/2 and Akt pathways. Mean percentage values of surviving RGCs (as compared with the contralateral nonaxotomized eye) averaged over the whole retina (center) as well as mean values of surviving $R G C s$ in various retinal eccentricities $(1 / 6,3 / 6,5 / 6)$ in $n t g$ and $V 1 t g$ mice (bottom). Animals receiving intravitreous injections of the solvent DMSO, the ERK-1/2 inhibitor PD98059, or the PI3K/Akt inhibitor LY294002 are shown, in addition to animals not receiving pharmacological treatments. Microphotographs of fluorogold-labeled RGCs in flatmounted retinas are also depicted (top). Note that the survival-promoting effect of VEGF is completely reversed both by the ERK-1/2 and PI3K/Akt inhibitors. Data are mean \pm SD values. Center, ${ }^{*} p<0.05,{ }^{* *} p<0.01$ compared with ntg mice; ${ }^{\dagger} p<0.05,{ }^{{ }^{+\dagger}} p<0.01$ compared with DMSO-treated V1tg mice. Bottom, ${ }^{*} p<0.05$ for comparison of V1tg with ntg mice; ${ }^{\ddagger} p<0.05$ for comparison of DMSO/PD98059 and DMSO/LY294002 with DMSO-treated V1tg mice (oneway ANOVA, followed by LSD tests). Scale bar, $50 \mu \mathrm{m}$.

rons and, as such, the NSE promoter is active in this cell type (Bernard et al., 1998), explaining the expression of the VEGF transgene in NSE-V1tg RGCs.

\section{VEGF protects RGC in vivo without influencing the} retinal vasculature

Survival-promoting properties of VEGF have been demonstrated previously in animal models of ALS (Azzouz et al., 2004; Storke- baum et al., 2005). In ALS, hemodynamic disturbances have been observed that were made responsible for motoneuron vulnerability (Oosthuyse et al., 2001; Lambrechts et al., 2003). For this reason, it was speculated that VEGF may exert its protection by stimulating vascular remodeling. Unlike in ALS, where VEGF deficiency resulted in spinal perfusion deficits related to the reduced angiogenesis (Oosthuyse et al., 2001), we could not detect any vascular abnormalities in the retinas of V1tg mice. Indeed, both the size of the main arterioles and capillary density were identical in nonaxotomized and axotomized ntg and V1tg retinas, ruling out major hemodynamic abnormalities induced by axotomy (which would invariably have resulted in vascular remodeling) and an enhanced angiogenesis induced by VEGF.

The absence of vascular abnormalities in the V1tg retina is noteworthy, as we previously observed an increased capillary density in the brains of V1tg mice (Vogel et al., 2004; Wang et al., 2005). The lack of an increased vessel density may be explained by the fact that VEGF levels were considerably lower in the V1tg retina compared with brain (human VEGF, $21.7 \pm 1.4 \mathrm{ng} / \mathrm{g}$ protein) (Wang et al., 2005). Lower VEGF levels in the retinas of V1tg mice, conversely, are explained by transgenic VEGF being overexpressed mainly by RGCs, which represent only a small subpopulation of cells in the retina.

We did not perform studies on vascular function in the mouse retina. Yet, in our previous studies in the brain, unaltered blood flow values were observed in V1tg animals compared with ntg mice (Vogel et al., 2004). The absence of major hemodynamic alterations in the V1tg brain, which exhibit increased capillary densities, together with lack of vascular abnormalities in the V1tg retina strongly argues against major hemodynamic alterations induced by human VEGF. Instead, direct neuroprotective effects of this growth factor are much more likely.

We already demonstrated in a model of middle cerebral artery occlusion that VEGF protects the brain against ischemia even under conditions in which cerebral blood flow is not improved by the enhanced capillary growth (Wang et al., 2005). Because VEGF inhibited caspase-3 activity (Wang et al., 2005), we concluded that anti-apoptotic effects were responsible for tissue survival. Using ON transection, a model of traumatically induced neuronal injury that clearly lacks vascular abnormalities, we now confirm that VEGF protects CNS neurons in vivo in a caspase-3dependent way.

\section{Role of vascular abnormalities in other VEGF-transgenic mouse lines}

By means of another mouse line overexpressing human VEGF under control of a truncated rhodopsin promoter, vascular abnormalities similar to those in diabetic retinopathy (including neovascularization, microaneurysms) have been reported previously in the retina (Lai et al., 2005; van Eeden et al., 2006; Shen et al., 2006). Compared with V1tg animals, VEGF levels were much higher in the retina of these rhodopsin-VEGF transgenic mice $(35.5 \pm 13.8 \mathrm{ng} / \mathrm{g}$ protein) (Lai et al., 2005), suggesting that the development of vascular changes depends on the VEGF level. Indeed, when analyzing two other muse lines with even higher VEGF levels (410.6 \pm 52.6 and $375.8 \pm 49.0 \mathrm{ng} / \mathrm{g}$ protein), Lai et al. (2005) found even more severe vascular pathologies including hemorrhages, retinal detachment, and cataracts. We could not observe vascular abnormalities in the retina of V1tg mice. The absence of vascular changes allowed us to study neuroprotective effects of VEGF. 

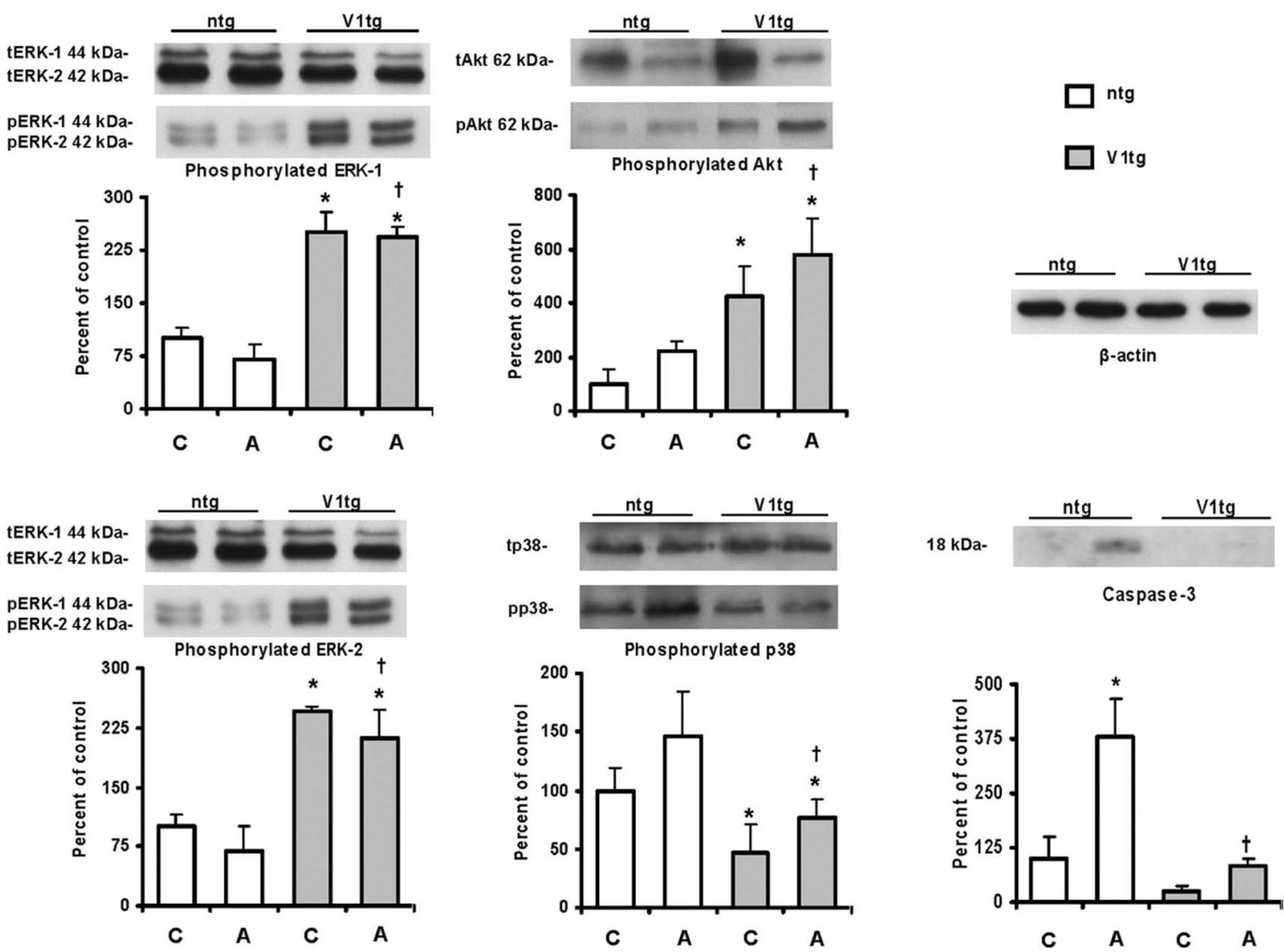

Figure 5. VEGF stimulates ERK-1/2 and Akt and inhibits p38 and caspase-3 pathways after RGC axotomy. Western blots with protein lysates of axotomized and contralateral nonaxotomized retinas of ntg and V1tg mice. Antibodies detecting both total (i.e., nonphosphorylated and phosphorylated) and phosphorylated signal factors were used. Note that VEGF increases phosphorylated (but not total) ERK-1/2 levels both in nonaxotomized and axotomized V1tg retinas. After axotomy, VEGF elevates phosphorylated Akt levels and furthermore reduces phosphorylated p38 and activated caspase-3. C, Nonaxotomized eye; $A$, axotomized eye. Data are mean \pm SD values ( $n=3$ different samples per group), normalized with corresponding blots for $\beta$-actin. ${ }^{*} p<0.05$ compared with nonaxotomized ntg mice; ${ }^{\dagger} p<0.05$ compared with nonaxotomized V1tg mice (one-way ANOVA, followed by LSD tests).

\section{Role of ERK-1/2 and PI3K/Akt pathways in the} neuroprotective function of VEGF

To elucidate pathways upstream of caspase- 3 mediating the neuroprotective properties of VEGF, we made use of histochemical studies that we combined with pharmacological experiments. We show that VEGFR-2 is expressed on RGCs and that VEGF stimulates ERK-1/2 and Akt pathways, at the same time inhibiting MAP kinase/p38. Because pharmacological inhibition of ERK1/2 (PD98059) and Akt (LY294002) abolished neuroprotection of VEGF, we conclude that the survival-promoting effect of VEGF depends on the dual activation of both ERK-1/2 and Akt pathways. It has been shown previously in vitro that VEGF protects cultured neurons by activating VEGFR-2, ERK-1/2, and Akt (Jin et al., 2000; Matsuzaki et al., 2001; Wick et al., 2002). Until now, no evidence existed that VEGFR-2 expression takes place on CNS neurons under physiological conditions in vivo. We now show that VEGFR-2 is expressed, at least on RGCs.

The ERK-1/2 and Akt pathways have been implicated previously in neuroprotection in case of other growth factors, such as brain-derived neurotrophic factor (Han and Holtzman, 2000) and erythropoietin (E. Kilic et al., 2005). ERK-1/2 acts as a transcriptional regulator in injured neurons (Irving and Bamford, 2002), whereas Akt stabilizes mitochondrial function by phos- phorylating Bad that consecutively releases $\mathrm{Bcl}-\mathrm{X}_{\mathrm{L}}$ inside mitochondria (Kilic et al., 2002). Once released, Bcl- $\mathrm{X}_{\mathrm{L}}$ prevents the formation of the mitochondrial permeability transition pore, decreases cytochrome $c$ release into the cytosol, and inhibits caspase-3 activity (Kilic et al., 2002).

\section{VEGF inhibits MAP kinase/p38}

In view of previous findings that VEGF stimulates MAP kinase/ p38 after brain hypoxia (Issbrücker et al., 2003), we were rather surprised to see that VEGF inhibits the p38 pathway after RGC axotomy. In brain hypoxia, p38 was previously identified as a marker reflecting blood brain barrier disturbances (Issbrücker et al., 2003). Because the blood-retina barrier remains intact after ON transection, differences in the experimental model may explain the low p38 phosphorylation level. In the injured CNS, p38 acts as stress-inducible kinase (Irving and Bamford, 2002). Hence, the reduced p38 phosphorylation state in V1tg retinas may reflect an attenuated stress response of protected RGCs.

\section{VEGF as therapeutic in degenerative brain diseases?}

Based on our observation that VEGF protects axotomized RGCs, which are CNS-derived neurons, from delayed degeneration, we 

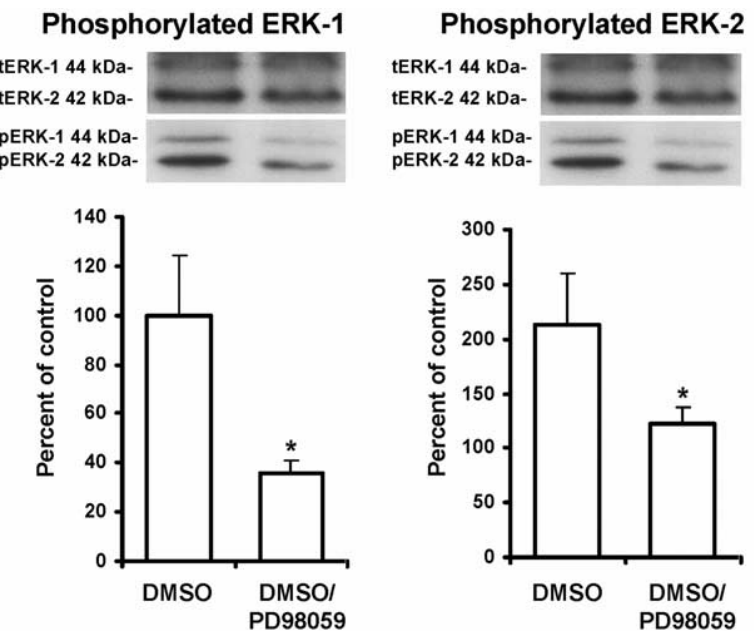

Phosphorylated Akt
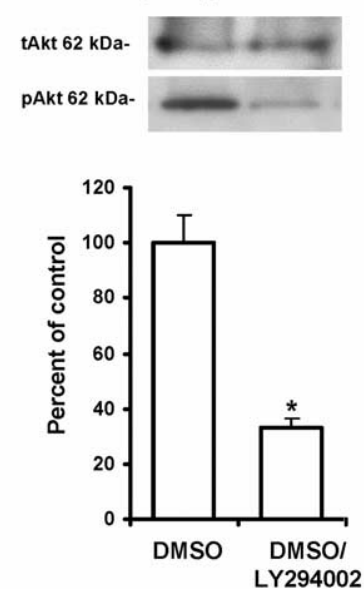

Figure 6. Intravitreous delivery of PD98059 and LY294002 inhibits ERK-1/2 and Akt phosphorylation in vivo. Western blots with protein lysates of nonaxotomized ntg retinas that were either treated with $0.5 \mu \mathrm{l}$ DMSO, DMS0/PD98059 (50 mM) or DMSO/LY294002 (100 mM). Animals received four consecutive injections of the signal inhibitors (days $0,4,7$, and 10 ) and were killed $1 \mathrm{~h}$ after the last injection. Data are mean \pm SD values ( $n=3$ samples per group), normalized with corresponding blots for $\beta$-actin. ${ }^{*} p<0.05$ compared with DMSO-treated mice (two-tailed t tests). Scale bar, $25 \mu \mathrm{m}$.

predict the clinical implementation of VEGF not only in ALS, but also in other neurodegenerative diseases of both brain and retina. The delivery of VEGF in humans is supported by clinical studies in patients with ischemic heart disease (Hendel et al., 2000; Henry et al., 2003) or limb ischemia (Baumgartner et al., 1998), in which VEGF was safely applied in the past. When considering VEGF as therapeutic, long-term side-effects must be taken into account, among which the enhanced angiogenesis and blood-brain barrier permeability deserve attention (Schoch et al., 2002; Wang et al., 2005). In addition to exogenous VEGF delivery, strategies upregulating VEGF expression may be considered. As such, statins have been shown to stimulate VEGF release in a very potent way (Cheng et al., 2005). Upregulating VEGF expression and release by pharmacological tools may allow us to make use of the beneficial effects of VEGF without risking its unfavorable actions under clinical conditions.

\section{References}

Azzouz M, Ralph GS, Storkebaum E, Walmsley LE, Mitrophanous KA, Kingsman SM, Carmeliet P, Mazarakis ND (2004) VEGF delivery with retrogradely transported lentivector prolongs survival in a mouse ALS model. Nature 429:413-417.

Baumgartner I, Pieczek A, Manor O, Blair R, Kearney M, Walsh K, Isner JM (1998) Constitutive expression of phVEGF $_{165}$ after intramuscular gene transfer promotes collateral vessel development in patients with critical limb ischemia. Circulation 97:1114-1123.

Bernard D, Dieni S, Rees S, Bernard O (1998) Physiological and induced neuronal death are not affected in NSE-bax transgenic mice. J Neurosci Res 52:247-259.

Cheng J, Zhang C, Jiang H, Li Y, Zhang L, Robin A, Katakowski M, Lu M, Chopp M (2005) Atorvastatin induction of VEGF and BDNF promotes brain plasticity after stroke in mice. J Cereb Blood Flow Metab 25:281-290.

Cramer SC, Chopp M (2000) Recovery recapitulates ontogeny. Trends Neurosci 23:265-271.

Garcia-Valenzuela E, Gorczyca W, Darzynkiewicz Z, Sharma SC (1994) Apoptosis in adult retinal ganglion cells after axotomy. J Neurobiol 25:431-438.

Han BH, Holtzman DM (2000) BDNF protects the neonatal brain from hypoxic-ischemic injury in vivo via the ERK pathway. J Neurosci 20:5775-5781.

Hendel RC, Henry TD, Rocha-Singh K, Isner JM, Kereiakes DJ, Giordano FJ,
Simons M, Bonow RO (2000) Effect of intracoronary recombinant human vascular endothelial growth factor on myocardial reperfusion. Evidence for a dose-dependent effect. Circulation 101:118-121.

Henry TD, Annex BH, McKendall GR, Azrin MA, Lopez JJ, Giordano FJ, Shah PK, Willerson JT, Benza RL, Berman DS, Gibson CM, Bajamonde A, Rundle AC, Fine J, McCluskey ER; VIVA Investigators (2003) The VIVA trial: Vascular endothelial growth factor in ischemia for vascular angiogenesis. Circulation 107:1359-1365.

Irving EA, Bamford M (2002) Role of mitogenand stress-activated kinases in ischemic injury. J Cereb Blood Flow Metab 22:631-647.

Isenmann S, Wahl C, Krajewski S, Reed JC, Bähr M (1997) Up-regulation of Bax protein in degenerating retinal ganglion cells precedes apoptotic cell death after optic nerve lesion in the rat. Eur J Neurosci 9:1763-1772.

Issbrücker K, Marti HH, Hippenstiel S, Springmann G, Voswinckel R, Gaumann A, Breier G, Drexler HCA, Suttorp N, Clauss M (2003) p38 MAP kinase: a molecular switch between VEGF-induced angiogenesis and vascular hyperpermeability. FASEB J 17:262-264.

Jin KL, Mao XO, Greenberg DA (2000) Vascular endothelial growth factor: direct neuroprotective effect in in vitro ischemia. Proc Natl Acad Sci USA 97:10242-10247.

Kilic E, Dietz GP, Hermann DM, Bähr M (2002) Intravenous TAT-Bcl- $\mathrm{X}_{\mathrm{L}}$ is protective after middle cerebral artery occlusion in mice. Ann Neurol 52:617-622.

Kilic E, Kilic Ü, Soliz J, Bassetti CL, Gassmann M, Hermann DM (2005) Brain-derived erythropoietin protects from focal cerebral ischemia by dual activation of ERK-1/-2 and Akt pathways. FASEB J 19:2026-2028.

Kilic Ü, Kilic E, Soliz J, Bassetti CL, Gassmann M, Hermann DM (2005) Erythropoietin protects from axotomy-induced degeneration of retinal ganglion cells by activating ERK-1/-2. FASEB J 19:249-251.

Klöcker N, Kermer P, Weisshaupt JH, Labes M, Ankerhold R, Bähr M (2000) Brain-derived neurotrophic factor-mediated neuroprotection of adult rat retinal ganglion cells in vivo does not exclusively depend on phosphatidyl-inositol-3'-kinase/protein kinase B signaling. J Neurosci 20:6962-6967.

Kobari M, Obara K, Watanabe S, Dembo T, Fukuuchi Y (1996) Local cerebral blood flow in motor neuron disease: correlation with clinical findings. J Neurol Sci 144:64-69.

Lai CM, Dunlop SA, May LA, Gorbatov M, Brankov M, Shen WY, Binz N, Lai YK, Graham CE, Barry CJ, Constable IJ, Beazley LD, Rakoczy EP (2005) Generation of transgenic mice with mild and severe retinal neovascularization. Br J Ophthalmol 89:911-916.

Lambrechts D, Storkebaum E, Morimoto M, Del-Favero J, Desmet F, Marklund SL, Wyns S, Thijs V, Andersson J, van Marion I, Al-Chalabi A, Bornes S, Musson R, Hansen V, Beckman L, Adolfsson R, Pall HS, Prats $\mathrm{H}$, Vermeire S, Rutgeerts P, et al. (2003) VEGF is a modifier of amyotrophic lateral sclerosis in mice and humans and protects motoneurons against ischemic death. Nat Genet 34:383-394.

Marti HH, Risau W (1998) Systemic hypoxia changes the organ-specific distribution of vascular endothelial growth factor and its receptors. Proc Natl Acad Sci USA 95:15809-15814.

Marti HJ, Bernaudin M, Bellail A, Schoch H, Euler M, Petit E, Risau W (2000) Hypoxia-induced vascular endothelial growth factor expression precedes neovascularization after cerebral ischemia. Am J Pathol 156:965-976.

Matsuzaki H, Tamatani M, Yamaguchi A, Namikawa K, Kiyama H, Vitek MP, Mitsuda N, Tohyama N (2001) Vascular endothelial growth factor rescues hippocampal neurons from glutamate-induced toxicity: signal transduction cascades. FASEB J 15:1218-1220.

Oosthuyse B, Moons L, Storkebaum E, Beck H, Nuyens D, Brusselmans K, van Dorpe J, Hellings P, Gorselink M, Heymans S, Theilmeier G, Dewerchin M, Laudenbach V, Vermylen P, Raat H, Acker T, Vleminckx V, 
Van Den Bosch L, Cashman N, Fujisawa H, et al. (2001) Deletion of the hypoxia-inducible element in the vascular endothelial growth factor promoter causes motoneuron degeneration. Nat Genet 28:131-138.

Schoch HJ, Fischer S, Marti HH (2002) Hypoxia-induced vascular endothelial growth factor expression causes vascular leakage in the brain. Brain 125:2549-2557.

Shen WY, Lai CM, Graham CE, Binz N, Lai YK, Eade J, Guidolin D, Ribatti D, Dunlop SA, Rakoczy PE (2006) Long-term global retinal microvascular changes in a transgenic vascular endothelial growth factor mouse model. Diabetologia 49:1690-1701.

Storkebaum E, Carmeliet P (2004) VEGF: a critical player in neurodegeneration. J Clin Invest 113:14-18.

Storkebaum E, Lambrechts D, Dewerchin M, Moreno-Murciano MP, Appelmans S, Oh H, Van Damme P, Rutten B, Man WY, De Mol M, Wyns S, Manka D, Vermeulen K, Van Den Bosch L, Mertens N, Schmitz C, Robberecht W, Conway EM, Collen D, Moons L, et al. (2005) Treatment of motoneuron degeneration by intracerebroventricular delivery of VEGF in a rat model of ALS. Nat Neurosci 8:85-92.

Sun Y, Jin K, Xie L, Childs J, Mao XO, Logvinova A, Greenberg DA (2003)
VEGF-induced neuroprotection, neurogenesis, and angiogenesis after focal cerebral ischemia. J Clin Invest 111:1843-1851.

van Eeden PE, Tee LB, Lukehurst S, Lai CM, Rakoczy EP, Beazley LD, Dunlop SA (2006) Early vascular and neuronal changes in a VEGF transgenic mouse model of retinal neovascularization. Invest Ophthalmol Vis Sci 47:4638-4645.

Vogel J, Gehrig M, Kuschinsky W, Marti HH (2004) Massive inborn angiogenesis in the brain scarcely raises cerebral blood flow. J Cereb Blood Flow Metab 24:849-859.

Waldemar G, Vorstrup S, Jensen TS, Johnsen A, Boysen G (1992) Focal reductions in cerebral blood flow in amyotrophic lateral sclerosis: a [99mTc]d,1-HMPAO SPECT study. J Neurol Sci 107:19-28.

Wang Y, Kilic E, Kilic Ü, Weber B, Bassetti CL, Marti HH, Hermann DM (2005) VEGF overexpression induces post-ischaemic neuroprotection, but facilitates haemodynamic steal phenomena. Brain 128:52-63.

Wick A, Wick W, Waltenberger J, Weller M, Dichgans J, Schulz JB (2002) Neuroprotection by hypoxic preconditioning requires sequential activation of vascular endothelial growth factor receptor and Akt. J Neurosci 22:64016407. 